DOI: https://doi.org/10.47405/mjssh.v5i9.482

\begin{tabular}{|c|c|}
\hline aid $x=$ & Malaysian Journal of Social Sciences and Humanities (MJSSH) \\
\hline Malaysian Journal of & Volume 5, Issue 9, September 2020 \\
\hline $\begin{array}{l}\text { Humantites } \\
\text { (moj-ssin) }\end{array}$ & e-ISSN : 2504-8562 \\
\hline & $\begin{array}{c}\text { Journal home page: } \\
\text { www.msocialsciences.com }\end{array}$ \\
\hline
\end{tabular}

\title{
Index Developing and Modelling the Factors of Academic Procrastination Among University Students
}

\author{
Ahmad Shahrizal Bin Amran1, Malina Binti Zulkifli1 \\ 1Universiti Utara Malaysia (UUM)
}

Correspondence: Ahmad Shahrizal Bin Amran (shahrizalamran96@gmail.com)

\begin{abstract}
Procrastination is a very common and becomes a problem among students nowadays. Procrastination will give the negative effect on the learning style of students, resulting in their low achievements in performing tasks and examination of maybe it will cause failure in the examinations, resulting in anxiety and also depression next lowering in their morale. This study aims to develop an index of procrastination and to model the factors of procrastination among university students. The factors that have been considered in this study are self-esteem, lack of motivation, overconfidence and social problems. The sample of 203 students of year 1 and year 3 had been selected using the stratified sampling. In developing the index, the weightage is very important. The index developed has been categorized into 4 categories, Low Academic Procrastination ( 0.24 and below), Average Academic Procrastination (0.25 to 0.50), Above Average Academic Procrastination (0.51 to 0.75) and High Academic Procrastination ( 0.76 and above). Study also reveal that there is no significant mean different in Gender, Year of Study and Type of Program. Furthermore, from the Pearson's Correlation Analysis result found that all the explanatory variables (lack motivation, self-esteem, confidence level and overconfidence) having the positive relation relationship with the dependent variable even it contribute the weak relationship. Among the four of independent variables only two variable were significant and 5 percent level of significance which are Lack of motivation and Overconfidence. Finding revealed that variable lack of motivation is the most influent factor towards academic procrastination.
\end{abstract}

Keywords: academic procrastination, lack of motivation, overconfidence, self-esteem, social problem

\section{Introduction}

Procrastination generally can be defined as a tendency towards delaying certain tasks (Murat \& Erdinc, 2017). It is a common phenomenon among people (Bakar \& Khan, 2016) and it comes out with negative effects such as depression and anxiety (Husain \& Sultan, 2010). There are two types of procrastination based on the study by Kim, Fernandez and Terrier (2017) which are active procrastination and passive procrastination. Active procrastination is defined as a person who already has intentional to procrastinate, but they can complete their task or job and achieve the level of satisfactory outcomes under time pressure. In contrast, passive procrastination is defined as a person who postponed their task or job until the last minute and is more likely to fail in completing their task under time pressure (Choi \& Moran, 2005). A procrastinator will be facing the negativity effect and stress over time, and it will lead to cause fatigue, lack of sleep, low in the immune system and lastly stomach issues (Godfrey, 2020). There are different situation among the procrastinator in a different 
environment. In the workplace, procrastinators will be stressed because they need to perform their tasks under pressure to catch up on the due date of submission. Failure in the submission of their task will make it even harder to perform another task and to keep a good job. At home, the simplest task that has promised to do also been procrastinating, and it will leads to tension because you hate being told what to do.

Procrastination is a very common and becomes a problem among students nowadays. Academic procrastination is defined as postponing completion of tasks such as assignments or preparing for an examination (Sirin, 2011). Bakar and Khan (2016) proved that from all hundred participants, none of them can be categorized as not procrastinators. It means that every students tends to become a procrastinator. Procrastination will give the negative effect on the learning style of students, resulting in their low achievements in performing tasks and examination of maybe it will cause failure in the examinations, resulting in anxiety and also depression next lowering in their morale. The competitive spirit can be loosed if they feel hesitation in beginning performing their academic work. Thus it will lead to lower quality of students (Hussain \& Sultan, 2010). Khan (2014) found that students tend to be aware and conscious of their procrastination. He reported that they want to be overcome in decreasing the level of procrastination in their daily routine during performing assignments or exams but they need to know the factor that leads them toward academic procrastination, so they can avoid it. For example, Sharma (2017) claimed that many studies indicate that lack of motivation is one of the factors that lead to procrastination through mixed research methodology. As procrastination seem to be a serious trend that is not only overlooked but poorly understood, therefore it is necessary to conduct a further study to identify other factors that can lead to academic procrastination among students. In this study, the multicriteria index, hypotheses testing and multiple regression analysis will be applied since past studies mostly using exploratory data analysis and focus more on the qualitative approach analysis. This index is only able to give a rough idea of procrastination and is unable to explain what is happening at micro levels, such as the significance level of the factors. There are four objectives in this study which are to identify the factors that influence the academic procrastination among students, to develop an index of academic procrastination among students, to determine whether there is the significant mean difference between academic procrastination between gender, year of study and type of program, and to model the factors of procrastination among university students considered in this study.

\section{Literature Review}

In every task and every field, procrastination may occur, in an academic, it is called as academic procrastination. Procrastination generally can be defined as a tendency toward delaying certain tasks (Murat \& Erdinc, 2017). Academic procrastination is defined as postponing completion of tasks such as assignments or preparing for an examination (Sirin, 2011). Murad (2017), Sharma (2017), and Khan (2014) stated that academic procrastination will lead to negative consequences such as academic failure and also will downgrade student's quality because procrastinators tend to spend more hours to begin doing the important task or assignment even in revising (Klasen, 2007).

A past study found that years of study and age are related to academic procrastination. Based on, Bakar and Khan (2016), they proved that from a hundred respondents, none of them can be categorized as not procrastinators. It means that every student has a tendency to become a procrastinator. There was a significant difference between student's gender towards academic procrastination (Lee, 2013).

A few past studies revealed that academic procrastination can be influenced by self-esteem. Low selfefficacy can be associated with self-esteem where it highly dependable connection with academic procrastination (Steel, 2007). Farran (2004) also stated that there is a significant association between academic procrastination and student's self-esteem and this variable is really highly recommended in academic procrastination studies (Lee, 2013). Lower in self-esteem will highly effect on academic procrastination among students (Klassen, Krawchuk \& Rajani, 2007). 
The lack of motivation is another factor that contributes to academic procrastination among the students. The level of student interest and effort towards that academics are reflected from academic motivation. This shows that when students are less motivated in a certain subject or study, they tend to procrastinate. Sharma (2017) and Husain and Sultan (2010) stated that students tend to procrastinate and unable to finished their tasks at a certain time due to lack of motivation and considered as the main causes (Khan et al., 2014).

Aderanti, Williams, Oyinloye and Uwanna (2013) concluded that there is a significant relationship between overconfidence behavior and academic procrastination. It will harm students if there is too much confidence in themself. Tends to overestimate certain conditions of one's information is the definition of overconfidence (Rouchier \& Tanimura, 2012). Someone will be more confident and less sensitivity towards success error when they always keep repeating on certain things and give the best result in their life or task (Hilary \& Menzly, 2006) and some expressed that less confidence is when they were not capable in managing their learning (Klasen, 2007). Past research by Aderanti et al. (2013) proved that students tend to be procrastinators, especially in academic procrastination if they have high confidence level or overconfidence.

Besides, academic procrastination also can be influenced by social problems and has been studied quite widely (Rouchier \& Tanimura, 2012). Pychyl (2008) stated that social problems also the factor that contributes to academic procrastination. In growing transitions, students often face adjustment problems. These adjustments often cause students to take anti-social actions which in turn lead to their delusions such as hanging around with their friends instead of performing their assignments or study. Students enjoying their time with the classmate (Hussain \& Sultan, 2010) and tend to procrastinate while they engaged by activities that were more fun and pleasant usually playing an online game or hang out with other friends just for released their stressful for some difficult tasks (Pychyl, Lee, Thibodeau \& Blunt, 2000).

From the literature review, the factors of self-esteem, lack of motivation, overconfidence and social problems are considered as the factors in this study. The past study also stated that gender and year of study must be included, so these variables will be included in the questionnaire in a demographic part. Since, as to my concern, there is no index that has been studied yet in this procrastination, hence, this study will develop a multicriteria index of procrastination. After that, the hypotheses testing will be applied in this study in order to determine the mean difference of procrastination between gender, years of study and type of program. Lastly, the multiple regression analysis is used to model the factors of academic procrastination among university students.

\section{Methodology}

\section{Data Collection}

In this study, primary data will be used. The data will be collected using the administered questionnaires. The population for this study is students who study in one of the faculty in Universiti Utara Malaysia. Stratified sampling is used in this study because of the non-homogenous population. The population has been stratified according to their year of study which is Year 1, 2 and 3. This study is interested in students in Year 1 and Year 3 because pass study by Lai, Badayai, Chandrasekaran and Kulasingam (2015) stated that Degree students in Year 1 and Year 3 has highly in procrastinate. The sample size in this study is 203 students from 428 population where 191 students from Year 1 and 237 students from Year 3.

In doing surveys, a questionnaire is considered as a useful option because it can cover a large and widely sample quicker and consider as cheaper compared to personal interviewing (Mathers, Fox, \& Hunn, 2007). In this study, the questionnaire is modified from pass study (Mathers et el., 2007). Next, this questionnaire used numerical scaling with 7 point scale (Joshi, Kale, Chandel, \& Pal, 2015). This questionnaire consists of 6 sections which are demographic profile (gender, year of study, CGPA, type 
of program), academic procrastination (10 items), self-esteem (10 items), social problem ( 7 items), lack of motivation (10 items) and confidence level (8 items).

\section{Reliability test}

Internal consistency of the item in a set of group was measured by using Cronbach's alpha. Cronbach alpha is a coefficient of reliability, not a statistical test. The range of Cronbach Alpha is between 0 and 1 , greater internal consistency if the value of Cronbach Alpha is closed to 1 . Based on rule of thumbs by George and Mallery (2016) when value of Cronbachs' alpha, $\alpha \geq 0.9$ indicate that excellent internal consistency, $0.8 \leq \alpha<0.9$ indicate good internal consistency, $0.7 \leq \alpha<0.8$ indicates acceptable internal consistency, $0.5 \leq \alpha<0.7$ indicates poor internal consistency and lastly $\alpha<0.5$ indicates unacceptable internal consistency.

\section{Method of Analysis}

\section{Index Developing}

Let's say there are $n$ options and each option comes with $k$ criteria. Based on the combination of information, this criterion will be sorted according to the degree of preference. To simplify the following illustration of a criterion-selection matrix with a row listing $n$ options $(i=1, ., ., N)$ and columns presenting the criterion, $(j=1, . ., K)$. The value of $x_{i j}$ represents the consideration for option $i$ in the criterion $j$. There are a few steps in developing an index. The steps are as follow:

\section{Step 1: Data Standardization}

If the units of each criterion measure are the same, the standardization is still to be considered when the variance between the criteria is too large. The standardization will stabilize the variance between the criteria, but if the variance does not differ the standardization may not be necessary.

Here are some ways in which standardization of the data can be used. Standardization by dividing the observation of a criterion with its optimum value.

If the optimal value is the maximum value so the standard value is:

$$
Z_{i j}=\frac{X_{i j}}{\max \left(X_{i j}\right)}
$$

If the optimal value is the minimum value so the standard value is:

$$
Z_{i j}=\frac{\min \left(X_{i j}\right)}{X_{i j}}
$$

The standardization is also can be done by taking into count the maximum and the minimum values at the same time. The resulting standard value is the fraction of the observed distance from the minimum value over the range of observation, the standard value is in interval 0 to 1 .

$$
Z_{i j}=\frac{X_{i j}-\min \left(X_{i j}\right)}{\max \left(x_{i j}\right)-\min \left(X_{i j}\right)}
$$

\section{Step 2: Weight Determination}

The weight of $w_{j}$ can be constructed in a variety of ways, according to the nature of the problem and data available. In the event of a significant correlation between weight loss criteria, it is 
DOI: https://doi.org/10.47405/mjssh.v5i9.482

necessary to consider the size of the correlation between the criteria. The appropriate weight should be proportional to the correlation coefficient. The weighting of the fourth criterion is derived by the formula

$$
w_{j}=\frac{\mathrm{r}_{j}}{\sum \mathrm{r}_{l}}, \mathrm{r}_{j}=\sum\left|\mathrm{r}_{j l}\right|
$$

with $\mathrm{r}_{i j}$ is the correlation coefficient between the criterion $i$ and the $j$ based on standard values

Where;

$$
\mathrm{r}_{i j}=\sum_{l=1}^{n}\left(\frac{z_{l i}-\bar{z}_{i}}{s_{i}}\right)\left(\frac{z_{l j}-\bar{z}_{j}}{s_{j}}\right)
$$

$$
\begin{gathered}
\bar{z}=\frac{1}{n} \sum_{l=1}^{n} z_{l j} \\
s_{j}{ }^{2}=\frac{1}{n-1} \sum_{l=1}^{n}\left(z_{l j}-\overline{z_{j}}\right)^{2}
\end{gathered}
$$

The change coefficient measures the degree of dispersion (change) to the mean value of the data. The smaller the coefficient of change then the smaller the change in the data. Change coefficient the fifth criterion, therefore, corresponds to the ratio of the standard deviation to the following mean:

$$
u_{j}=\frac{s_{j}}{\overline{z_{j}}}
$$

\section{Step 3: Index Developing}

One way to rank is by priority using a composite index of various criteria. After the loading is performed the composite index for each choice is obtained using a weighted score. A composite score for option $i$ along with,

$$
\begin{gathered}
g_{i}=w_{1} z_{i 1}+w_{2} z_{i 2}+\cdots+w_{k} z_{i k}=\sum_{j} w_{j} z_{i j} \\
\text { with, } \\
\sum_{j} w_{j}=1, w_{j} \geq 0
\end{gathered}
$$

If the standardization is not performed the composite index is equivalent

$$
g_{i}=w_{1} x_{i 1}+w_{2} x_{i 2}+\cdots+w_{k} x_{i k}
$$

\section{Independent T-Test}

The independent t-test is used in comparing the significant difference between the mean of two groups. The equality of variances should be run first using Levene's test, and the test is significant when the p-value is less than 0.05 . The hypothesis for t-test;

$H_{0}: \mu_{1}=\mu_{2}$

$H_{1}: \mu_{1} \neq \mu_{2}$ 


\section{Analysis of variance (ANOVA)}

One-way analysis of variance (ANOVA) is used in identifying the significant differences between the mean of three or more independent groups. The test is significant when the p-value is less than 0.05. The hypothesis for ANOVA;

$H_{0}: \mu_{1}=\mu_{2}=\mu_{3}$

$H_{1}$ : Atleast one mean is different.

\section{Multiple Linear Regression Model}

The model of multiple linear regression in this study is $Y=\beta_{0}+\beta_{i} X_{i}+\varepsilon$. This model is used in explaining the relationship between the academic procrastination (dependent variable) with selfesteem, social problem, overconfidence, and lack of motivation. All the independent variables are interval scales.

The assumptions for multiple linear regression model must be checked before proceed with the analysis:

- Data for each explanatory variable must be normally distributed.

- $\varepsilon \sim N(0, \sigma)$. The error term is normally distributed.

- The variance is constant.

- Absence of multicollinearity.

\section{Result and Findings}

\section{Reliability and Validity Test}

The pilot test was performed to validate the instrument (questionnaire). The pilot test was performed on experts in modifying the ambiguous expression. In the pilot test, thirty students from the faculty were chosen as respondents to answer the questionnaire and to ensure the adequate semantics of the words used. Respondents were asked to give their comments towards the questionnaire on the list of items, instrument length, scales, wording and format. The value of Cronbach's alpha is 0.891 is exceeds the minimum value of 0.6. Thus it can be concluded that all the items in the questionnaire are reliable (Gallais, Gagnon, Forgues, Cote \& Laberge, 2017). Based on the rule of thumbs by George and Mallery (2016) Cronbach's alpha with 0.891 consider as a good internal consistency.

\section{Demographic Information}

The majority respondent are Female with 153 students (75.4\%) while others are Male with 50 students (24.6\%). Besides, total for students from Year 1 is 91 with $44.8 \%$ and from Year 3 is 112 students with $55.2 \%$. Based on sampling method being applied researcher consider Year of Study as strata and the respondents are taken randomly by their current year of study. Net, the percentage respondent based on Program taken by SQS's students. Fifty-five respondent are from Bachelor of Science with Honors (Business Mathematics) with 27.1\% followed by 62 students from Bachelor of Science with Honors (Industrial Statistics) with 30.5\% and 82 students from Bachelor of Science with Honors (Decision Science) with 42.4\%. Lastyly, mostly SQS students got CGPA with 3.00$3.49(47.8 \%)$ followed by 3.50-4.00 (37.4\%) and 2.50-2.99 (14.8\%). Resulting that none of students from SQS got CGPA 2.49 and below. 
DOI: https://doi.org/10.47405/mjssh.v5i9.482

Table 1: The Frequency table for the demographic profile

\begin{tabular}{llcc}
\hline & & Freq & $\begin{array}{c}\text { Percent } \\
\mathbf{( \% )}\end{array}$ \\
\hline Gender & Female & 153 & 75.4 \\
Year of Study & Male & 50 & 24.6 \\
\multirow{4}{*}{ Type of Program } & Year 1 & 91 & 44.8 \\
& Year 3 & 112 & 55.2 \\
& B. Sc. Hons. (Business Mathematics) & 55 & 27.1 \\
CGPA & B. Sc. Hons. (Industrial Statistics) & 62 & 30.5 \\
& B. Sc. Hons. (Decision Science) & 86 & 42.4 \\
& 2.50 - 2.99 & 30 & 14.8 \\
& $3.00-3.49$ & 97 & 47.8 \\
\hline
\end{tabular}

\section{Index Developing}

\section{Step 1: Data standardization}

The data has been standardized by dividing the observation of a criterion with maximum value based on the equation (1).

\section{Step 2: Weight determination}

The weight in this study has been determined using the correlation based since the event of a significant correlation between weight loss criteria. The result of the correlation for each variable shown in Table 2.

Table 2: The Correlation result for Explanatory Variable

\begin{tabular}{ccccc}
\hline Variable & Self_Est & Lack_Moti & Soc_Prob & Conf_Level \\
\hline Self_Est & 1.000 & 0.063 & 0.391 & 0.425 \\
Lack_Moti & 0.063 & 1.000 & 0.386 & 0.486 \\
Soc_Prob & 0.391 & 0.386 & 1.000 & 0.636 \\
Conf_Level & 0.425 & 0.486 & 0.636 & 1.000 \\
\hline
\end{tabular}

From Table 2, there is a strong positive relationship between confidence level with a social problem. Which mean that high confidence level leads to a high issue in social problem. A weak positive relationship between confidence level with self-esteem and lack of motivation. Since there is a significant correlation between the variable then the weighting value should take into account the size of the correlation and the weighting value calculated using the equation (4) and the result shown in Table 3. Based on Table 3, the variable confidence level can be considered as the most influential factor that contributes to academic procrastination, followed by a social problem, lack of motivation and lastly self-esteem.

Table 3: Initial value, weighted and variable rank for each variable using the correlation based method

\begin{tabular}{cccc}
\hline Variable, $\boldsymbol{j}$ & Initial Value, $\boldsymbol{r}_{\boldsymbol{j}}$ & Weighted, $\boldsymbol{w}_{\boldsymbol{j}}$ & Variable Rank \\
\hline Self_Est & 1.879 & 0.214 & 4 \\
Lack_Moti & 1.935 & 0.221 & 3 \\
Soc_Prob & 2.413 & 0.275 & 2 \\
Conf_Level & 2.547 & 0.290 & 1 \\
\hline
\end{tabular}



DOI: https://doi.org/10.47405/mjssh.v5i9.482

\begin{tabular}{lll}
\hline TOTAL & 8.774 & $\sum w_{j}=1.000$ \\
\hline
\end{tabular}

\section{Step 3: Index Developing}

Then the index value has been calculated using the equation (5). The value of index is between 0 to 1. Index in this study has been categorized into 4 categories using quartile for further explanation by Lodha, Sharma, Dsousza, Marathe, Rawal and De Sousa (2019). Table 3 shows the range for each index related to this study. Table 4 shows the percentage for 203 SQS'S students based on their range value. Majority of students are Above Average Academic Procrastination with $79 \%$ (160 students) followed by Average Academic Procrastination, 11\% (23 students), then, High Academic Procrastination 10\% (20 students) and lastly none of students who got Low Academic Procrastination.

Table 4 Range of Index for Academic Procrastination

\begin{tabular}{ccc}
\hline Index value & Range & No. of Students \\
\hline 0.24 and below & Low Academic Procrastination & 0 \\
0.25 to 0.50 & Average Academic Procrastination & 23 \\
0.51 to 0.75 & Above Average Academic Procrastination & 160 \\
0.76 and above & High Academic Procrastination & 20 \\
\hline
\end{tabular}

The greater value in the index indicates that higher in academic procrastination. First ranking for academic procrastinator resulting from students from Year 1, which means that this student has the highest attitude towards academic procrastination. From this first ten (10) students, five (5) students from Year 1 and five (5) students from Year 3, hence it can be concluded that there is no significant difference between these two groups.

The last ten (10) students who has average attitude in academic procrastination. The lowest value in index indicate that lowest in academic procrastination. Last ranking for academic procrastinator resulting by student from Year 3, which mean that this student has the lowest attitude towards academic procrastination. From this last ten (10) students, five (5) students from Year 1 and five (5) students from Year 3, hence can be conclude that there is no significant difference between this two groups.

Table 5: Index ranking based on First and Last ten (10) students

\begin{tabular}{ccccc}
\hline Matric Num & Gender & Year of Study & Index & Ranking \\
\hline \multirow{5}{*}{273554} & First ten (10) students & & \\
272396 & Male & Year 1 & 0.96 & 1 \\
254749 & Female & Year 1 & 0.93 & 2 \\
253068 & Female & Year 3 & 0.84 & 3 \\
255577 & Male & Year 3 & 0.84 & 4 \\
256345 & Female & Year 3 & 0.83 & 5 \\
273737 & Male & Year 3 & 0.80 & 6 \\
255716 & Female & Year 1 & 0.80 & 7 \\
262884 & Male & Year 3 & 0.79 & 8 \\
273959 & Female & Year 1 & 0.79 & 9 \\
& Female & Year 1 & 0.79 & 10 \\
270044 & Last ten (10) students & & \\
253648 & Female & Year 1 & 0.46 & 194 \\
272170 & Female & Year 3 & 0.46 & 195 \\
254067 & Female & Year 1 & 0.46 & 196 \\
\hline
\end{tabular}



DOI: https://doi.org/10.47405/mjssh.v5i9.482

\begin{tabular}{lccll}
\hline 271639 & Female & Year 1 & 0.44 & 198 \\
272877 & Female & Year 1 & 0.44 & 199 \\
256832 & Female & Year 3 & 0.43 & 200 \\
256333 & Male & Year 3 & 0.40 & 201 \\
271956 & Male & Year 1 & 0.39 & 202 \\
252892 & Female & Year 3 & 0.25 & 203 \\
\hline
\end{tabular}

\section{Independent T-Test}

For the equality of variance test, it can be concluded variances are equal between gender (male and female students) and also between the year of study (Year 1 and Year 2) on academic procrastination since the p-values in Levene's test are greater than 0.05 for both groups. The t-test for equality of means shows that there is no significant mean difference between male students and female students also between Year 1 and Year 3, on academic procrastination since the p-value is greater than 0.05 .

Table 6: Table of Independent T-Test

\begin{tabular}{llllllll}
\hline $\begin{array}{l}\text { Academic } \\
\text { Procrastination }\end{array}$ & $\begin{array}{l}\text { Levene's Test } \\
\text { F }\end{array}$ & Sig. & \multicolumn{2}{l}{$\begin{array}{l}\text { t-test for Equality of Means } \\
\text { df }\end{array}$} & $\begin{array}{l}\text { Sig. (2- } \\
\text { tailed) }\end{array}$ & $\begin{array}{l}\text { Mean } \\
\text { Differences }\end{array}$ & $\begin{array}{l}\text { Std. Error } \\
\text { Differences }\end{array}$ \\
\hline Gender & 0.2824 & 0.5956 & 1.770 & 201 & 0.0780 & 0.3207 & 0.1811 \\
Year of Study & 0.0576 & 0.8104 & -1.235 & 201 & 0.2182 & -0.1946 & 0.1575 \\
\hline
\end{tabular}

\section{Analysis of Variance (ANOVA)}

Table 7 show that there is no significant difference in academic procrastination among students from different type of program, since the p-value 0.508 are greater than 0.05 .

Table 7: The ANOVA table for Academic Procrastination and Type of Program

\begin{tabular}{cccccc}
\hline & Sum of Squares & df & Mean Square & F & Sig. \\
\hline Between the Program & 1.703 & 2 & 0.851 & 0.679 & 0.508 \\
Within the Program & 250.825 & 200 & 1.254 & & \\
Total & 252.527 & 202 & & & \\
\hline
\end{tabular}

\section{Checking for the Assumption Multiple Linear Regression}

\section{Normality Test}

All the variables are normally distributed since the value for skewness and kurtosis is between - 2 and +2 (George \& Mallery, 2016). Kim (2013) stated that for medium sample sized 50 to 300 if the absolute Z-value are less than 3.29 the variables will considered as a normal distribute.

Table 8: The Skewness, Kurtosis and Z-test Value for Dependent and Explanatory Variables

\begin{tabular}{crrrrrr}
\hline & \multicolumn{2}{c}{ Statistic } & \multicolumn{2}{c}{ Standard error } & \multicolumn{2}{c}{ Z-test } \\
VARIABLE & skewness & kurtosis & skewness & kurtosis & skewness & kurtosis \\
\hline Aca_Procras & -0.3445 & -0.4875 & 0.1707 & 0.3397 & -2.0188 & -1.4350 \\
\hline
\end{tabular}



DOI: https://doi.org/10.47405/mjssh.v5i9.482

\begin{tabular}{crrrrrr}
\hline Self_Est & 0.1373 & -0.3035 & 0.1707 & 0.3397 & 0.8043 & -0.8935 \\
Lack_Moti & -0.0349 & 0.4052 & 0.1707 & 0.3397 & -0.2045 & 1.1927 \\
Soc_Prob & 0.1782 & 0.4938 & 0.1707 & 0.3397 & 1.0442 & 1.4536 \\
Conf_Level & 0.0448 & 1.0041 & 0.1707 & 0.3397 & 0.2628 & 2.9557 \\
\hline
\end{tabular}

The normal P-P plot Figure 1, shows that the error term can be assumed normally distributed since all of the points are lying approximately along the straight lines. Based on the scatter plot in Figure 2 , it can be concluded that the variance of the error terms is constant since it shows there are no obvious patterns.
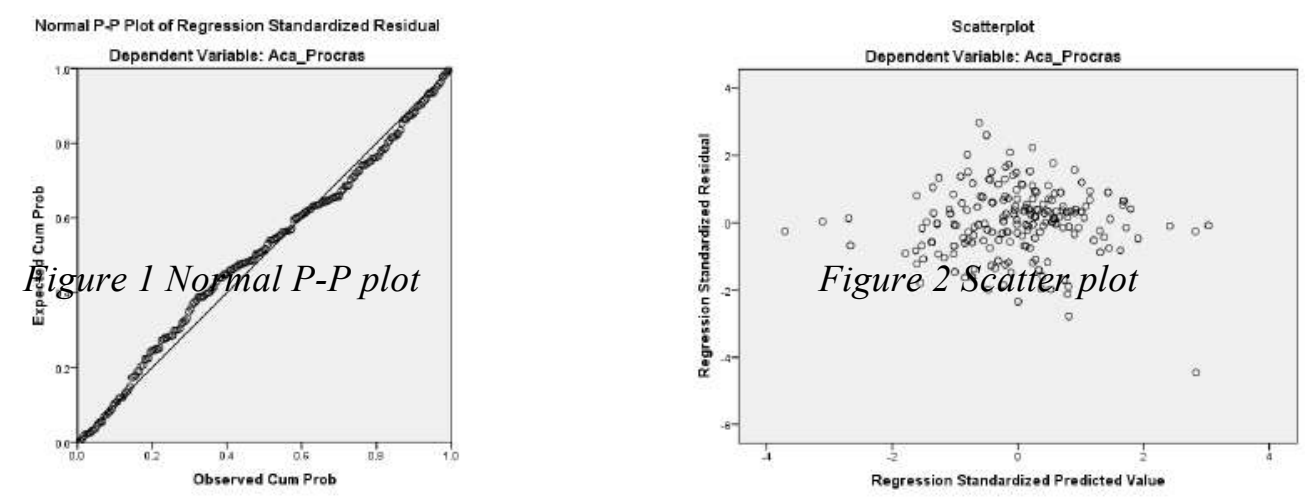

Multicollinearity is one of the assumptions in the multiple linear regression model. From the Table 9 can conclude that there is no existence of multicollinearity since the value of tolerance are more than 0.1 and the VIF are less than 10 .

\section{Multiple Regression Model}

After fulfill the assumption, the regression model starts with the full model. In the first step of the backward method, variable Social Problem ware eliminated due to the lower partial correlation as all the predictor variables are include in the regression equation. Self-esteem second variable were be eliminated. Resulting the model with two variable which are Lack of Motivation and Confidence Level with Adj-R ${ }^{2} 0.502$.

Table 9: The Coefficient Table for the best model

\begin{tabular}{ccccccc} 
Variable & B & $\begin{array}{c}\text { Std. } \\
\text { Error }\end{array}$ & t & Sig. & Tolerance & VIF \\
\hline (Constant) & -0.035 & 0.308 & -0.114 & 0.909 & \\
Lack_Moti & 0.618 & 0.068 & 9.134 & $<0.001$ & 0.764 & 1.309 \\
Conf_Level & 0.382 & 0.073 & 5.242 & $<0.001$ & 0.764 & 1.309 \\
\multicolumn{2}{c}{$\mathrm{R}^{2}=0.507$, Adj-R ${ }^{2}=0.502, F=103.00, \mathrm{p}$-value $=<0.001$} & \\
\hline
\end{tabular}

From Table 9, it can be conclude that the model with two variable are significant since the p-value are less than 0.05. Thus, can be conclude that the variable Lack Motivation and Confidence Level were significant since the $\mathrm{p}$-value of this two variable are less than 0.05 . The final model is given in Equation 1.

Academic Procrastination $=-0.035+0.618 *$ Lack_Moti $+0.382 *$ Conf_Level - Equation 1

The interpretation of the coefficient for the significant variable as follow: 


\section{Lack of Motivation: 0.618}

In every unit scale increase in lack motivation, 0.618 unit scale will increase in academic procrastination, while variable confidence level held constant.

\section{Confidence Level: 0.382}

In every unit scale increase in confidence level, 0.618 unit scale will increase in academic procrastination, while variable lack motivation held constant.

\section{Conclusion}

There are two priority tasks in this study, which are to develop an index for academic procrastination and to modelling the factors that lead to academic procrastination and among university students based on their level of overconfidence, lack of motivation, self-esteem and social problems. The demographics (Gender, Year of Study and Type of Program) also been tested towards academic procrastination.

There are 4 range has been categorized based on the index developed which are Low Academic Procrastination (0.24 and below), Average Academic Procrastination (0.25 to 0.50), Above Average Academic Procrastination (0.51 to 0.75) and High Academic Procrastination (0.76 and above). The result showed that the majority of students are in range Above Average Academic Procrastination with $79 \%$ of them. This result supported by Bakar and Khan (2016) which their study concluded that none of the students can be categorized as not procrastinators. Based on the index ranking by students, it shows that there is no different between the Year 1 and Year 3 students towards the academic procrastination. This index can be used in identifying level of procrastination among the students.

Next, this study reveals that there is no significant mean difference between gender, year of study and type of program. Which means that level of academic procrastination among this group are the same because of all students tend to be a procrastinator, UKEssay (2018) on their research conclude that both male and female are equally procrastinated their task.

Furthermore, the study found that all the factors (self-esteem, lack of motivation, confidence level and overconfidence) having a positive relationship with academic procrastination even it contributes to the weak relationship. Only two from the four factors tested are significant with academic procrastination. Lack of motivation and overconfidence are the factors that significantly contribute to students' academic procrastination. Aderanti et al. (2013) stated that overconfidence and academic procrastination has a significant difference which means that academic procrastination will occur if they got high overconfidence in themselves.

Besides, this study revealed that the most influential factor towards academic procrastination is lack of motivation which is the highest value of coefficient 0.618 compare to overconfidence. Khan et. el. (2014) also stated that lack of motivation is considered as the root cause of academic procrastination and Rakes and Dunn (2010) stated that all students will face in lack of motivation. In conclusion, procrastination behaviors are common phenomenon that carried from the past history and even today it still casts its shadow on mankind. This study were consider as successful as all the objectives were achieved with the limitation of study and area covered as well, some of the finding might be contrast from pass study due to scope of study and limitation of study.

\section{References}

Ackerman, D. S., \& Gross, B. L. (2005). My instructor made me do it: Task characteristics of procrastination. Journal of Marketing education, 27(1), 5-13.

Aderanti, R. A., Williams, T. M., Oyinloye, C. A., \& Uwanna, N. C. (2013). Academic procrastination, overconfidence and parental unrealistic expectations as correlates of academic 
rebelliousness among some Nigerian undergraduate students. In African Symposium (Vol. 13, No. 1, pp. 12-8).]

Balkis, M., \& Erdinç, D. U. R. U. (2017). Gender differences in the relationship between academic procrastination, satifaction with academic life and academic performance. Electronic Journal of Research in Educational Psychology, 15(1), 105-125.

Bakar, Z. A., \& Khan, M. U. (2016). Relationships between self-efficacy and the academic procrastination behaviour among university students in Malaysia: A general perspective. Journal of Education and Learning, 10(3), 265-274.

Cerino, E. S. (2014). Relationships between Academic Motivation, Self-Efficacy, and Academic Procrastination. Psi Chi Journal of Psychological Research, 19(4).

Choi, J. N., \& Moran, S. V. (2009). Why not procrastinate? Development and validation of a new active procrastination scale. The Journal of social psychology, 149(2), 195-212.

Gallais, B., Gagnon, C., Forgues, G., Côté, I., \& Laberge, L. (2017). Further evidence for the reliability and validity of the Fatigue and Daytime Sleepiness Scale. Journal of the neurological sciences, 375, 23-26.

Godfrey, H. (2020, Feb. 8). The Negative Effects of Procrastination on Your Life. Retrieved from https://www.theauthenticpath.com/the-negative-effects-of-procrastination-on-your-life

George, D., \& Mallery, P. (2016). IBM SPSS statistics 23 step by step: A simple guide and reference. Routledge.

Hilary, G., \& Menzly, L. (2006). Does past success lead analysts to become overconfident?. Management science, 52(4), 489-500.

Hussain, I., \& Sultan, S. (2010). Analysis of procrastination among university students. ProcediaSocial and Behavioral Sciences, 5, 1897-1904.

Jawale, K. V. (2012). Methods of sampling design in the legal research: Advantages and disadvantages. Online International Interdisciplinary Research Journal, 2(6), 183-190.

Jemain, A. A. (2004). Penentuan wajaran dalam pembinaan indeks pelbagai kriteria. Matematika, 20, 77-85.

Joshi, A., Kale, S., Chandel, S., \& Pal, D. K. (2015). Likert scale: Explored and explained. British Journal of Applied Science \& Technology, 7(4), 396.

Khan M. J., Arif H., Noor S. S., Muneer S. (2014). Academic Procrasrination among Male and Female University and College Students. WU Journal of Social Sciences, Winter 2014, Vol. 8, No.2, 6570.

Kim, H.-Y. (2013). Statistical notes for clinical researchers: assessing normal distribution (2) using skewness and kurtosis. Restorative Dentistry \& Endodontics, 38(1), 52.

Kim, S., Fernandez, S., \& Terrier, L. (2017). Procrastination, personality traits, and academic performance: When active and passive procrastination tell a different story. Personality and Individual differences, 108, 154-157.

Klassen, R. M., Krawchuk, L. L., \& Rajani, S. (2008). Academic procrastination of undergraduates: Low self-efficacy to self-regulate predicts higher levels of procrastination. Contemporary Educational Psychology, 33(4), 915-931.

Lai, C. S., Badayai, A. R., Chandrasekaran, K., Lee, S. Y., \& Kulasingam, R. (2015). An exploratory study on personality traits and procrastination among university students. American Journal of Applied Psychology, 4(3), 21-26.

Lee, E. (2005). The relationship of motivation and flow experience to academic procrastination in university students. Journal of Genetic Psychology, 166, 5-14.

Lodha, P., Sharma, A., Dsouza, G., Marathe, I., Dsouza, S., Rawal, S., ... \& De Sousa, A. (2019). General Procrastination Scale: Development of Validity and Reliability. International Journal of Medicine and Public Health, 9(3).

Loeb, S., Dynarski, S., McFarland, D., Morris, P., Reardon, S., \& Reber, S. (2017). Descriptive Analysis in Education: A Guide for Researchers. NCEE 2017-4023. National Center for Education Evaluation and Regional Assistance.

Mathers N, Fox N. and Hunn A. (2007). Surveys and Questionnaires. The NIHR RDS for the East Midlands / Yorkshire \& the Humber.

Nigel, M., Fox, N., \& Hunn, A. (2009). Surveys and Questionnaires. The NIHR Research Design Service for Yorkshire \& the Humber. www. rds-eastmidlands. nihr. ac. uk, 1, 147. 
DOI: https://doi.org/10.47405/mjssh.v5i9.482

Pychyl, T. A., Lee, J. M., Thibodeau, R., \& Blunt, A. (2000). Five Days of Emotion: An Experience Sampling Study of Undergraduate Student Procrastination. Journal of Social Behavior and Personality, 15, 239-254.

Pychyl, T. (2008). Worry Helps Me Cope: A Metacognitive Belief Linked To Procrastination, Carleton University Ottawa, Canada.. Retrieved fromwww.psychology today blogs.htm accessed on December 21, 2009.

Rahim, S. A. (2008). Media dan generasi muda. Institut Penyelidikan Pembangunan Belia Malaysia.

Rakes, G. C., \& Dunn, K. E. (2010). The Impact of Online Graduate Students' Motivation and SelfRegulation on Academic Procrastination. Journal of Interactive Online Learning, 9(1).

Rouchier, J., \& Tanimura, E. (2012). When overconfident agents slow down collective learning. Simulation, 88(1), 33-49.

Russell, F. E., Boyle, J. F., \& Chiverrell, R. C. (2019). NIRS quantification of lake sediment composition by multiple regression using end-member spectra. Journal of Paleolimnology, 62(1), 73-88.

Sharma, D., Sharma, M., \& Sharma, T. (2017). Procrastination versus planned rocrastination - A study report. International Journal of Humanities and Social Sciences 6(1).

Steel, P. (2007). The nature of procrastination: A meta-analytic and theoretical review of quintessential self-regulatory failure. Psychological bulletin, 133(1), 65.

UKEssays. (November 2018). Relationship Of Gender Differences Procrastination And Academic Achievement Psychology Essay. Retrieved from https://www.ukessays.com/essays/psychology/relationship-of-genderdifferencesprocrastination-and-academic-achievement-psychology-essay.php?vref $=1$

Yahaya, A., Abdul, A. H., and Ismail, S., (2010) Budaya Lepak Di Kalangan Remaja Di: Implikasi Kepada Pembentukan Institusi Keluarga Melayu. Budaya Lepak Di Kalangan Remaja Di: Implikasi Kepada Pembentukan Institusi Keluarga Melayu . pp. 1-9. 